\title{
Comparative evaluation of Intrathecal Fentanyl with different doses of Bupivacaine on lower limb surgery
}

\author{
Sharan R. ${ }^{1}$, Jarewal V. ${ }^{2}$, Singh H. ${ }^{3}$, Attri J.P. ${ }^{4}$ \\ ${ }^{1}$ Dr Radhe Sharan, Professor, ${ }^{2}$ Dr Vishal Jarewal, Senior Resident, ${ }^{3}$ Dr Harjeet Singh, Assistant Professor, ${ }^{4}$ Dr Joginder \\ Pal Attri, Professor, All authors are affiliated with Department of Anaesthesia, Government Medical College, Amritsar, \\ Punjab, India.
}

Address for Correspondence: Dr Harjeet Singh, D-17/1212, Street No-2, Kartar Nagar, Chhehtra, Amritsar. Pin-143105. Email: drharjeet1960@gmail.com

\begin{abstract}
Introduction: Intrathecal administration of opioids and local anaesthetics provides good analgesia. Fentanyl potentiates the afferent surgical blockade and improves both intra and post operative analgesia. The synergism between intrathecal opioids and local anaesthetics achieves a reliable spinal anaesthesia with minimal hypotension. The optimal doses and dilutions of intrathecal combination of bupivacaine and fentanyl remain a subject of discussion. Therefore, we designed this study to compare the effects of different doses of hyperbaric bupivacaine $0.5 \%$ (10 mg, $12.5 \mathrm{mg}, 15 \mathrm{mg})$ with fentanyl 25 microgram in subarachnoid block on quality of anaesthesia and recovery. Objectives: To observe sensory and motor blockcharacteristics and effects of different doses of bupivacaine on haemodynamic parameters. Method: A prospective randomized study was carried out on three groups of 20 each. Group A patients were given $0.5 \%$ hyperbaric bupivacaine $10 \mathrm{mg}$, fentanyl $25 \mu \mathrm{g}$ and $0.9 \%$ normal saline $1.5 \mathrm{ml}$. Group B patients were given with $0.5 \%$ hyperbaric bupivacaine $12.5 \mathrm{mg}$, fentanyl $25 \mu \mathrm{g}$ and $0.9 \%$ normal saline $1 \mathrm{ml}$. Group C patients were given $0.5 \%$ hyperbaric bupivacaine $15 \mathrm{mg}$, fentanyl $25 \mu \mathrm{g}$ and $0.9 \%$ normal saline $0.5 \mathrm{ml}$. Results: Duration of sensory block was prolonged in

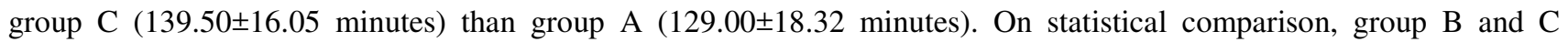
(126.25 \pm 15.29 minutes and $132.75 \pm 10.70$ minutes respectively) had significant prolonged duration of motor block than group A (114.00 \pm 18.11 minutes). Conclusion: Fentanyl $25 \mu \mathrm{g}$ with $0.5 \%$ hyperbaric bupivacaine $12.5 \mathrm{mg}$ is superior in terms of characteristics of sensory and motor block and haemodynamic stability.
\end{abstract}

Key words: Spinal anaesthesia, Hyperbaric Bupivacaine, Fentanyl

\section{Introduction}

The International Association for the study of Pain has defined Pain as "an unpleasant sensory and emotional experience associated with actual or potential tissue damage or described in terms of such damage". The aim of post operative pain relief is to prevent subjective discomfort, in addition to early mobilization and shortened hospital stay and subsequently to enhance restoration of physiological function of operated region [1].

The increasing acceptance of spinal anaesthesia can be attributed to the simplicity of the technique and equipment, economy, maintenance of consciousness and spontaneous respiration, muscle relaxation, minimal disturbances of body chemistry, less intra operative

\footnotetext{
Manuscript received: $16^{\text {th }}$ December 2017

Reviewed: $26^{\text {th }}$ December 2017

Author Corrected: $4^{\text {th }}$ January 2018

Accepted for Publication: $8^{\text {th }}$ January 2018
}

bleeding, decreased incidence of post operative nausea, vomiting and aspiration, prolonged post operative analgesia and a pleasant recovery from anaesthesia. The discovery of spinal opioid receptors and neuraxial administration of opioids has revolutionized the concept of intra operative and post operative pain management [2]. Clinical observations has shown that the intrathecal administration of combination of opioids and local anaesthetics provides good analgesia to patients with less intense motor blockade than that produced by local anaesthetics alone [3].

An amide group local anaesthetic bupivacaine has acceptable longer duration of action, profound conduction blockade and significant separation of sensory anaesthesia and motor blockade [4]. It is four times more potent than lidocaine. It does not show 


\section{Original Research Article}

tachyphylaxis and has lower incidence of transient radicular symptoms. Thereby it has become more popular for neuraxial blockade $[5,6]$. There is increasing interest in using various additives to spinal local anaesthetics with the goal of decreasing the dose of local anaesthetics, enhancing the duration of action and minimizing the adverse the effects of local anaesthetics. Central neuraxial administration of opioids in conjunction with local anaesthetics not only improves the quality of intra operative analgesia but also prolong the duration and effectiveness of post operative analgesia [7]. Fentanyl is a lipophilic opioid and is 100 times more potent than morphine. Its lipophilicity minimizes its rostral migration to respiratory centre, thereby not causing delayed respiratory depression. It potentiates the afferent surgical blockade and improves both intra and post operative analgesia [8]. It has been suggested that the synergism between intrathecal opioids and local anaesthetics may make it possible to achieve reliable spinal anaesthesia with minimal hypotension using a mini dose of local anaesthetic [9].

Regional anaesthesia is well tolerated by geriatric patients. In non geriatric population, the association of fentanyl and local anaesthetics improves the sensory block in intra and post operative period [10]. The effects associated with intrathecal fentanyl appear to be influenced by dose of administration, as higher doses (50 microgram) cause early respiratory depression[11], while 40 microgram increases the incidence of itching and nausea [12]. The optimal doses and dilutions of intrathecal combination of bupivacaine and fentanyl remain a subject of discussion. Therefore, we designed this study to compare the effects of different doses of hyperbaric bupivacaine $0.5 \%(10 \mathrm{mg}, 12.5 \mathrm{mg}, 15 \mathrm{mg})$ with fentanyl 25 microgram in subarachnoid block on quality of anaesthesia and recovery.

Aims and objectives of this study are

- to observe the onset and level of sensory block

- the duration of sensory and motor block

- comparison of effect of different doses of bupivacaine on haemodynamic parameters

\section{Material and Method}

Place of study: Government medical college, Amritsar

Type of study: A prospective randomized study

Sampling methods: Sample size was calculated keeping in view at most $5 \%$ risk with minimum $80 \%$ power of study and 5\% significance level (significant at $95 \%$ confidence interval)
Inclusion criteria: 60 adult patients of ASA grade I and II undergoing lower limb surgery.

Exclusion criteria: Patients who were unwilling for the procedure, or who were pregnant or lactating or with coagulation disorders and neurological disorders, or with any signs of sepsis, previous injury, deformity or previous surgery of spine, or with morbid obesity, or any anticipated difficulty in regional anaesthesia or allergy to study drug or with any life threatening disease.

After obtaining approval from institutional ethical committee, 60 adult patients of either sex belonging to ASA grade I and II admitted to Government medical college, Amritsar for lower limb surgery under spinal anaesthesia were randomly divided into three groups of 20 each. Group A patients were given subarachnoid block with $0.5 \%$ hyperbaric bupivacaine $10 \mathrm{mg}$, fentanyl $25 \mu \mathrm{g}$ and $0.9 \%$ normal saline $1.5 \mathrm{ml}$. Group B patients were given subarachnoid block with $0.5 \%$ hyperbaric bupivacaine $12.5 \mathrm{mg}$, fentanyl $25 \mu \mathrm{g}$ and $0.9 \%$ normal saline $1 \mathrm{ml}$. Group $\mathbf{C}$ patients were given subarachnoid block with $0.5 \%$ hyperbaric bupivacaine $15 \mathrm{mg}$, fentanyl $25 \mu \mathrm{g}$ and $0.9 \%$ normal saline $0.5 \mathrm{ml}$. A thorough pre anaesthetic examination was done a day before surgery and written informed consent was taken from all the patients. Patients having bleeding diathesis, on anti coagulant, with raised intra cranial tension, with deformity in spinal column, suffering from bronchial asthma, cardiac or respiratory or renal or CNS disease, who were mentally retarded or allergic to local anaesthetics and drugs to be used were excluded from the study. All routine investigations were ordered.

All patients were given tablet diazepam $10 \mathrm{mg}$ a night before surgery and injection glycopyrrolate $0.2 \mathrm{mg} 45$ minutes before surgery. An intravenous line was secured and preloading was done with ringer's lactate $10 \mathrm{ml} \mathrm{kg}$ ${ }^{1}$ over the period of 20 to 30 minutes. Heart rate, non invasive blood pressure, respiratory rate, ECG, and oxygen saturation were monitored during the surgery.

Under strict aseptic conditions, lumbar puncture was performed at the level of L3-L4 intervertebral space in lateral position using $26 \mathrm{G}$ needle after infiltrating the skin with 0.5 to $1 \mathrm{ml}$ of $2 \%$ lidocaine. After obtaining the free flow of CSF, solution of fentanyl, bupivacaine and normal saline was administered as per requirement in each group by the anaesthesiologist not participating in the study. Patient was then made into supine position immediately and spread of anaesthesia was assessed every two minutes by pin prick method. The time of onset of adequate analgesia that is sensory blockade 


\section{Original Research Article}

upto T 10 was noted. Maximum upper level of sensory block and time to attain maximum block was recorded. Heart rate, non invasive blood pressure, respiratory rate, oxygen saturation were recorded at five minutes interval for first ten minutes and then at every ten minutes interval. Episodes of intra operative hypotension and bradycardia were also noted. Hypotension was treated with rapid infusion of fluids and incremental doses of ephedrine hydrochloride $(5 \mathrm{mg})$. Bradycardia was treated with atropine $(0.1 \mathrm{mg})$ and nausea, vomiting with injection ondansetron $\left(0.1 \mathrm{mg} \mathrm{kg}^{-1}\right)$ intravenously.

Patients with inadequate block who require supplemental general anaesthesia were excluded from the study. In post operative period duration of sensory block was noted until the time to regression to T12 level. Motor blockade was also recorded and graded at the end of surgery by using modified bromage scale. Time to request for analgesia was also noted. Vitals were recorded every at five minutes interval for first ten minutes, at every ten minutes interval for two hours and thereafter every half hour till analgesia was requested.

All patients were observed for side effects of the procedure. Statistical methods: Observations were made in tabulated form and analysed. Inter group mean values were compared using on way ANOVA with post HOC test Tukey HSD.

Experimental groups: 60 adult patients of either sex belonging to ASA grade I and II were randomly divided into three groups of 20 each.

\section{Results}

In the present study all the three groups were comparablewith respect to age, sex ratio, height, weight, duration of surgery and pre operative baseline haemodynamic parameters as shown in table: 1 .

Table-1: Demographic distribution and Baseline parameters.

\begin{tabular}{|c|c|c|c|c|c|c|c|c|c|}
\hline \multirow[t]{2}{*}{$\begin{array}{c}\text { Gro } \\
\text { up }\end{array}$} & \multirow[t]{2}{*}{$\begin{array}{c}\text { Age } \\
\text { (in years) }\end{array}$} & \multicolumn{2}{|c|}{$\begin{array}{c}\text { Sex } \\
(\% \text { age }) \\
\end{array}$} & \multirow[t]{2}{*}{$\begin{array}{l}\text { Height } \\
\text { (in cm) }\end{array}$} & \multirow[t]{2}{*}{$\begin{array}{c}\text { Weight } \\
\text { (Kg) }\end{array}$} & \multirow{2}{*}{$\begin{array}{c}\text { Heart rate } \\
\text { (per } \\
\text { minute) }\end{array}$} & \multirow{2}{*}{$\begin{array}{l}\text { Systolic } \\
\text { blood } \\
\text { pressure }\end{array}$} & \multirow{2}{*}{$\begin{array}{l}\text { Diastolic } \\
\text { blood } \\
\text { pressure }\end{array}$} & \multirow{2}{*}{$\begin{array}{l}\text { Duration of } \\
\text { surgery (in } \\
\text { minutes) }\end{array}$} \\
\hline & & $\mathrm{M}$ & $\mathrm{F}$ & & & & & & \\
\hline A & $51.55 \pm 18.00$ & 16 & 4 & $168.30 \pm 5.74$ & $67.80 \pm 5.13$ & $82.50 \pm 8.80$ & $132.70 \pm 13.30$ & $80.30 \pm 7.52$ & $85.00 \pm 22.35$ \\
\hline B & $48.70 \pm 15.36$ & 16 & 4 & $165.98 \pm 6.20$ & $68.40 \pm 5.29$ & $85.80 \pm 12.73$ & $131.50 \pm 18.29$ & $81.40 \pm 7.82$ & $83.50 \pm 28.15$ \\
\hline $\mathrm{C}$ & $47.70 \pm 19.80$ & 17 & 3 & $166.98 \pm 5.28$ & $68.05 \pm 6.18$ & $87.35 \pm 11.80$ & $128.10 \pm 14.53$ & $77.80 \pm 9.40$ & $88.00 \pm 27.83$ \\
\hline
\end{tabular}

The onset of adequate analgesia and achievement of maximum upper level of sensory block was comparable in all the three groups. However, time taken to achieve maximum upper level of sensory block was more in group A (14.00 \pm 4.35 minutes) as compared to group C (12.00 \pm 3.75 minutes), but there was no significant difference between group A and B and group B and C as shown in table: 2.Durationof sensory block was prolonged in group C $139.50 \pm 16.05$ minutes) as compared to group A $(129.00 \pm 18.32$ minutes $)$. However there was no statistically significant variation seen between group $\mathrm{A}$ and $\mathrm{B}$ or $\mathrm{B}$ and $\mathrm{C}$ or Aand $\mathrm{C}$.

Table-2: Sensory block characteristics.

\begin{tabular}{|c|c|c|c|c|c|c|}
\hline Group & $\begin{array}{c}\text { Time take to achieve } \\
\text { maximum sensory block } \\
\text { (in minutes) }\end{array}$ & $\begin{array}{l}\text { Inter group } \\
\text { comparison }\end{array}$ & p value & $\begin{array}{c}\text { Duration of } \\
\text { sensory block (in } \\
\text { minutes) } \\
\end{array}$ & $\begin{array}{l}\text { Inter group } \\
\text { Comparison }\end{array}$ & p value \\
\hline A & $14.00 \pm 4.35$ & $\mathrm{~A} v / \mathrm{s} \mathrm{B}$ & $0.531^{\mathrm{NS}}$ & $129.00 \pm 18.32$ & A v/s B & $0.963^{\mathrm{NS}}$ \\
\hline B & $12.60 \pm 4.16$ & $\mathrm{~A} \mathrm{v} / \mathrm{s} \mathrm{C}$ & $0.280^{\mathrm{NS}}$ & $130.50 \pm 19.59$ & $\mathrm{~A} v / \mathrm{s} \mathrm{C}$ & $0.166^{\mathrm{NS}}$ \\
\hline $\mathrm{C}$ & $12.00 \pm 3.75$ & $\mathrm{~B}$ v/s C & $0.889^{\mathrm{NS}}$ & $139.50 \pm 16.05$ & $\mathrm{~B} v / \mathrm{s} \mathrm{C}$ & $0.264^{\mathrm{NS}}$ \\
\hline
\end{tabular}

NS $=$ Non Significant $(p>0.05)$

In inter group comparison of motor block characteristics, bromage scale of 1 was shown by 19 patients of group A and 3 patients each in group B and C, whereas bromage scale of 3 was shown by only 3 patients in group A, 9 in group B and maximum 11 in group $\mathrm{C}$. The difference was statistically significant thus indicating a significantly higher intensity motor block in group C patients. On statistical comparison, group B and C (126.25 \pm 15.29 minutes and $132.75 \pm 10.70$ minutes 
respectively) had significant prolonged duration of motor block than group A (114.00 \pm 18.11 minutes) as shown in table: 3

Table-3: Motor block characteristics.

\begin{tabular}{|c|c|c|c|c|c|c|c|}
\hline \multirow[t]{2}{*}{ Group } & \multicolumn{4}{|c|}{ Bromage scale of motor } & \multirow{2}{*}{$\begin{array}{c}\text { Duration in } \\
\text { minutes }\end{array}$} & \multirow{2}{*}{$\begin{array}{l}\text { Inter group } \\
\text { comparison }\end{array}$} & \multirow[t]{2}{*}{ p value } \\
\hline & $\mathbf{0}$ & 1 & 2 & 3 & & & \\
\hline A & 2 & 9 & 6 & 3 & $114.00 \pm 18.11$ & $\mathrm{~A} \mathrm{v} / \mathrm{s} \mathrm{B}$ & $0.033^{\mathrm{S}}$ \\
\hline $\mathrm{B}$ & 0 & 3 & 8 & 9 & $126.25 \pm 15.29$ & $\mathrm{~A} \mathrm{v} / \mathrm{s} \mathrm{C}$ & $0.001^{\mathrm{S}}$ \\
\hline $\mathrm{C}$ & 1 & 3 & 5 & 11 & $132.75 \pm 10.70$ & $\mathrm{~B} \mathrm{v} / \mathrm{s} \mathrm{C}$ & $0.364^{\mathrm{NS}}$ \\
\hline
\end{tabular}

NS $=$ Non Significant $(\mathrm{p}>0.05) ; \mathrm{S}=$ Significant $(\mathrm{p}<0.05)$

The mean time to request for first analgesia was 237.35 \pm 50.46 minutes, $259.20 \pm 70.72$ minutes and $259.10 \pm 65.39$ minutes for group A, B and C respectively and was comparable. Duration of effective analgesia (time from the onset of adequate analgesia to the time of first request of analgesia) was $231.35 \pm 50.60$ minutes, $253.30 \pm 71.60$ minutes and $252.80 \pm 66.24$ minutes in group A, B and C respectively. No statistical difference was seen amongst the three groups.

On inter group comparison of intraoperative heart rate between group A,B and C, decrease was gradual and comparable at all time intervals.

The fall of intra operative systolic blood pressure in group B was significant at 20 minutes $(\mathrm{p}<0.05)$ as compared to group $\mathrm{A}$. In group $\mathrm{A}$ and $\mathrm{C}$, the fall in group $\mathrm{C}$ at 10 minutes and onwards till 40 minutes was statistically significant. In group $\mathrm{B}$ and $\mathrm{C}$, the fall was gradual and comparable at all time intervals. In inter group comparison of intraoperative diastolic blood pressure, the fall in group A and B was gradual and comparable. The fall in intra operative diastolic blood pressure in group A and C was statistically significant at 10 minutes onwards till 90 minutes, while in group B and C the fall was statistically significant at 30 minutes onwards till 70 minutes.

There was no episode of any significant variation in oxygen saturation or any respiratory depression in any of the three groups.

In case of inter group comparison of post operative heamodynamics, systolic blood pressure remained comparable at all time intervals but statistically significant in group A and $\mathrm{C}$ at 0 to 30 minutes, while diastolic blood pressure in group $\mathrm{A}$ and $\mathrm{C}$, group $\mathrm{B}$ and $\mathrm{C}$ was statistically significant at 0 to 150 minutes. Sedation, pruritis, nausea, shivering, hypotension were observed in all the groups. Incidence of pruritis was more as compared to other side effects in all the three groups (20\%, 30\% and 20\% respectively) and very few patients required management in form of chlorphenaramine and hydrocortisone injections.

\section{Discussion}

Opioids are increasingly being administered intrathecally as adjuvants to local anaesthetics [13]. Opioids in conjunction with local anaesthetics improve the quality of intraoperative analgesia and prolongs the duration of postoperative analgesia.

Our study evaluated the effects of combination of fentanyl $25 \mu \mathrm{g}$ with three different doses of $0.5 \%$ hyperbaric bupivacaine (10, 12.5 and $15 \mathrm{mg}$ ) in spinal anaesthesia amongst three groups and compared the onset and level of sensory block along with cardiovascular variables intraoperatively and sensory as well as motor block along with duration of analgesia postoperatively.

Galinski et al in their study concluded that in elderly patients adding $25 \mu \mathrm{g}$ fentanyl to bupivacaine during spinal anaesthesia did not alter the onset and duration of motor and sensory block but significantly decrease the pain intensity in 
immediate postoperative period [14]. The onset of analgesia was rapid in the present study and there was no statistically significant difference between the three groups regarding onset of analgesia (time taken to attain T10 level).

The maximum upper level of sensory block was up to the level of T4 in all the three groups. Group C patients (who received $15 \mathrm{mg}$ bupivacaine with $25 \mu \mathrm{g}$ fentanyl) attained maximum upper level of sensory block in lesser time and had prolonged duration of sensory block as compared to other two groups.

The difference was statistically significant and this finding was in accordance with the study done by Ben David B et al who observed the intensification as well as prolongation of duration of sensory block without increasing the intensity of motor block with addition of $10 \mu \mathrm{g}$ fentanyl in small dose of bupivacaine for ambulatory arthroscopic surgeries [9].

The time of request of analgesia and duration of effective analgesia in present study was slightly less in group A patients (with 10mg bupivacaine) but the difference was statistically insignificant in comparison with other two groups ( $\mathrm{p}>0.10$ ). But $25 \mu \mathrm{g}$ fentanyl prolonged the duration of [post operative analgesia to same extent in all the three groups. Studies conducted by Singh C et al[11] and Rousell JR et al[15] also observed the prolongation of post operative analgesia with addition of fentanyl in bupivacaine in spinal anaesthesia.

Present study observed that addition of $25 \mu \mathrm{g}$ fentanyl in $15 \mathrm{mg}$ bupivacaine (group C) increased the intensity and duration of motor blockade while addition of same amount of fentanyl in $10 \mathrm{mg}$ bupivacaine (group B) resulted in short lasting motor block with statistically significant difference from other two groups.

The similar results were obtained by study conducted by Kuusniemi et al who found that addition of $25 \mu$ fentanyl in $5 \mathrm{mg}$ bupivacaine resulted in short lasting motor block as compared to larger doses of bupivacaine ( 7.5 to $10 \mathrm{mg}$ ).

Thus recovery from spinal anaesthesia gets prolonged as dose of bupivacaine is increased with fixed dose of fentanyl while duration of analgesia remained similar [16].

There was slight fall in heart rate in all the three groups in the present study but no episode of bradycardia was seen. $40 \%$ in group C, $10 \%$ in group B and only $4 \%$ in group A show hypotension. The higher incidence in group C is due to higher dose of bupivacaine. Such a clinical finding was predicted by experimental work which showed that the decrease in sympathetic efferent activity after spinal anaesthesia with bupivacaine is dose related and intrathecal fentanyl neither by itself nor in combination with bupivacaine causes any depression of sympathetic activity [17].

Our results are in accordance with study conducted by Lee BB which also showed a significantly lesser incidence of hypotension with smaller dose of $1.25 \mathrm{mg}$ bupivacaine with $25 \mu$ fentanyl as compared to $2.5 \mathrm{mg}$ bupivacaine with $25 \mu \mathrm{g}$ fentanyl[10].

In the current study, pruritis of mild to moderate intensity was most common side effect. Lui $\mathrm{S}$ et al also found that the addition of fentanyl $20 \mu \mathrm{g}$ to bupivacaine led to pruritis [18]. All the side effects observed in the present study were comparable amongst the three groups as dose of fentanyl was same. This was in accordance to study conducted by Herman NL et al who showed the dose dependent relation of fentanyl with analgesia, pruritis and ventilatory depression [19]. Our study used fentanyl $25 \mu \mathrm{g}$ which is unlikely to cause any respiratory depression as demonstrated by Varrassi et al which demonstrated the early respiratory depression in elderly patient by $50 \mu \mathrm{g}$ fentanyl as compared to $25 \mu \mathrm{g}[20]$.

\section{Conclusion}

The combination of fentanyl $25 \mu \mathrm{g}$ with $0.5 \%$ hyperbaric bupivacaine $12.5 \mathrm{mg}$ is more useful, acceptable clinically and superior in terms of characteristics of sensory and motor block, duration of analgesia and greater haemodynamic stability as compared to other two combinations. The synergistic analgesic effect of fentanyl with $12.5 \mathrm{mg}$ bupivacaine helped in attaining better quality of analgesia along with excellent recovery profiles.

Previous studies have not used fentanyl $25 \mu \mathrm{g}$ with $0.5 \%$ hyperbaric bupivacaine $12.5 \mathrm{mg}$. So analgesic effects and sensory as well as motor block characteristics due to combination of fentanyl and bupivacaine were not up to that mark as attained in present study. 
Original Research Article

\section{Contribution by authors}

\begin{tabular}{|c|c|c|c|c|}
\hline & Contributor 1 & Contributor 2 & $\begin{array}{c}\text { Contributor 3 } \\
\text { (corresponding author) }\end{array}$ & Contributor 4 \\
\hline Concepts & $\sqrt{ }$ & $\sqrt{ }$ & $\sqrt{ }$ & $\sqrt{ }$ \\
\hline Design & $\sqrt{ }$ & $\sqrt{ }$ & $\sqrt{ }$ & $\sqrt{ }$ \\
\hline $\begin{array}{c}\text { Definition of intellectual } \\
\text { content }\end{array}$ & $\sqrt{ }$ & $\sqrt{ }$ & $\sqrt{ }$ \\
\hline Literature search & $\sqrt{ }$ & $\sqrt{ }$ & $\sqrt{ }$ \\
\hline Clinical studies & $\sqrt{ }$ & $\sqrt{ }$ & $\sqrt{ }$ \\
\hline Experimental studies & $\sqrt{ }$ & $\sqrt{ }$ & $\sqrt{ }$ \\
\hline Data acquisition & $\sqrt{ }$ & $\sqrt{ }$ & $\sqrt{ }$ & $\sqrt{ }$ \\
\hline Data analysis & $\sqrt{ }$ & $\sqrt{ }$ & $\sqrt{ }$ & $\sqrt{ }$ \\
\hline Statistical analysis & $\sqrt{ }$ & $\sqrt{ }$ & & $\sqrt{ }$ \\
\hline Manuscript preparation & & & & \\
\hline Manuscript editing & & & & \\
\hline Manuscript review & & & & \\
\hline Guarantor & & & & \\
\hline
\end{tabular}

Funding: Nil, Conflict of interest: None.

Permission of IRB: Yes

\section{References}

1. Kehlet H, Rung GW, Callesen T. Postoperative opioid analgesia: time for a reconsideration? J Clin Anesth. 1996 Sep;8(6):441-5.

2. Dripps RD and Vandam LD. Long term follow up of patients who received 10,098 spinal anaesthesic: failure to discover major neurological sequelae. JAMA 1954; 156:1484.

3. Pittoni G, Toffoletto F, Calcarella G, Zanette G, Giron GP. Spinal anesthesia in outpatientknee surgery: 22- gaugeversus 25-gauge Sprotteneedle. Anesth Analg. 1995 Jul; 81(1):73-9.

4. Covino BG. Pharmacology of local anaesthetic agents. Br J Anaesth. 1986 Jul;58(7):701-16.

5. Kartha RK, Velamatis, Penas L, Aravapalli R, Lavine L. Epidural butorphanol for postoperative analgesia. Anaesthesiology 1987;67:A235.

6. Paterson GM, McQuay HJ, Bullingham RE, Moore RA. Intradural morphine and diamorphine. Dose response studies. Anaesthesia. 1984 Feb; 39(2):113-7.

7. Dickenson $\mathrm{AH}$. Mechanisms of the analgesic actions of opiates and opioids. Br Med Bull. 1991 Jul;47(3): 690-702.
8. Hunt CO, Datta S, Hauch M, Ostheimer GW, Hesting L, Naulty JS. Perioperative analgesia with subaracjnoid fentanyl - bupivacaine. Anaesthesiology 1987;67:A621.

9. Ben-David B, Maryanovsky M, Gurevitch A, Lucyk C, Solosko D, Frankel R, Volpin G, DeMeo PJ. A comparison of minidose lidocaine-fentanyl and conventional-dose lidocaine spinal anesthesia. Anesth Analg. 2000 Oct;91(4):865-70.

10. Lee BB, Ngan Kee WD, Hung VYS, Wong ELY. Combined spinal epidural in labor: Comparison of two doses of intrathecal bupivacaine with fentanyl. $\mathrm{Br} \mathrm{J}$ Anaesth 1999;83(6):868-71.

11. Singh C, Trikha A and Saxena A. Spinal anaesthesia with bupivacaine and fentanyl.Anaesthesiaand clinical pharmacology 1999;15:291-94.

12. Biswas BN, Rudra A, Bose BK, Nath S, Chakrabarty S, Bhattacharjee S. Intrathecal fentanyl with hyperbaric bupivacaine improves analgesia during caesarean section and in early postoperative period. Indian J Anaesth 2002; 46(6):469-72.

13. Akerman B, Arwestrom E, Post C. Local anaesthetics potentiates spinal morphine antinociception. Anaesthesia Analgesia 1988;67: 943-48. 
Original Research Article

14. Fernandez-Galinski D, Rué M, Moral V, Castells C, Puig MM. Spinal anesthesia with bupivacaine and fentanyl in geriatric patients. AnesthAnalg. 1996 Sep;83 (3): 537-41.

15. Roussel JR, Heindel L. Effects of intrathecal fentanyl on duration of bupivacaine spinal blockade for outpatient knee arthroscopy. AANA J. 1999 Aug;67(4): 337-43.

16. Kuusniemi KS, Pihlajamäki KK, Pitkänen MT, Helenius HY, Kirvelä OA. The use of bupivacaine and fentanyl for spinal anesthesia for urologic surgery. Anesth Analg. 2000 Dec;91(6):1452-6.

17. Wang C, Chakrabarti MK, Whitman JG. Specific enhancement by fentanyl of effects of intrathecal bupivacaine on nociceptive afferent but not on efferent pathways in dogs. Anaesthesiology1993;79:766-73.
18. Liu S, Chiu AA, Carpenter RL, Mulroy MF, Allen HW, Neal JM, Pollock JE. Fentanyl prolongs lidocainespinal anesthesia without prolonging recovery. Anesth Analg. 1995 Apr;80(4):730-4.

19. Herman NL, Choi KC, Afflek PJ, Calocott R, Braklin R, Singhal A, Andreasen A, Gadalla F, Fong J, Gomillion MC, Martman JK, Koff HD, Lee SHR, Decar TKV. Analgesia, pruritis and ventilation exhibit a dose - response relationship in parturients receiving intrathecal fentanyl during caesarean section. Anaesth Analg 1999;89:378-83.

20. Varrassi G, Celleno D, Capogna G, Costantino P, Emanuelli M, Sebastiani M, Pesce AF, NivD. Ventilatory effects of subarachnoidfentanyl in the elderly. Anaesthesia. 1992 Jul;47(7):558-62.

\section{How to cite this article?}

Sharan R, Jarewal V, Singh H, Attri J.P. Comparative evaluation of Intrathecal Fentanyl with different doses of Bupivacaine on lower limb surgery. Int J Med Res Rev 2018;6(01):3-9. doi:10.17511/ijmrr. 2018.i01.02. 